\title{
Characteristics and the formation mechanism of the heterogeneous microfractures in the tight oil reservoir of Ordos Basin, China
}

\author{
Shuheng Du \\ State Key Laboratory of Nonlinear Mechanics, Institute of Mechanics, Chinese Academy of Sciences, Beijing 100190, China
}

\section{A R T I C L E I N F O}

\section{Keywords:}

Microfracture

Formation mechanism

Tight oil

Sandstone

Characterization

\begin{abstract}
A B S T R A C T
This study aims to investigate the characteristics and the formation mechanism of the heterogeneous microfractures in the upper Triassic Yanchang Formation tight oil reservoir of Ordos Basin, China with some new perspectives. In this paper, we define two sets of parameters describing the size and geometry of microfractures by using Feret diameter calculation and Legendre ellipse fitting. Then the unidirectional fracture zone and multidirectional fracture zone are also be defined.

Results of the microfractures characterization show that when the lengths of microfractures are less than 600 $\mu \mathrm{m}$ (and the widths are less than $90 \mu \mathrm{m}$ ), the above two set of data show a good linear positive correlation, but when the lengths of microfractures continue to increase, the widths of microfractures begin to deviate from the linear relationship and gradually diverge. This indicates that the lengths and widths of microfractures are not strictly and steadily correlated, but their correlation has a threshold value. If the lengths of microfractures increase due to the change of internal or external stress, when the length value is higher than a certain value, the opening process of microfractures will begin to lose stability, and the widths will change gradually irregularly.

Once the compaction process reach a certain extent, some of the microfractures opened previously will be temporarily closed, which will greatly promote the process of pressure-solution, and thus increase the microfracture tortuosity. The length, width, solidity and boundary tortuosity of microfractures could be used to distinguish two zones include the multi-directional fracture zone from the unidirectional fracture zone.

The conclusion would provide the important scientific basis for the EOR applications of tight oil.
\end{abstract}

\section{Introduction}

Tight oil is a type of crucial unconventional resource, and its enrichment rule and effective exploitation method are the focus and hot spot of domestic and foreign scholars (Ge et al., 2015; Du et al., 2015, 2016; Zhu et al., 2019; Du et al., 2020). As we all know, as the significant attributes of unconventional oil and gas reservoirs, microfractures have been paid more and more attention (Wang et al., 2018; Du et al., 2018a, 2018b; Dai et al., 2019). The formation process of microfractures is closely related to the state of in-situ stress, mineral composition and distribution. It has dual effects on oil and gas migration and exploitation. On the one hand, microfractures provide new effective transport channels for tight reservoirs, which increase the diversity of fluid trajectories and facilitate fluid migration. Especially in the process of hydraulic fracturing, microfractures are easily activated and connected by artificial fractures, thus providing the extremely important flow space for fluids. On the other hand, the continuous development of microfractures is easy to connect the production wells and injection wells which would cause water flooding and water channeling. It would prevent the oil and gas exploitation (Blunt, 2001; Dong and Blunt, 2009; Williamsstroud et al., 2013; Liang, 2016; Karimpouli et al., 2017). Therefore, fine and quantitative characterization of microfractures in tight reservoirs is a vital scientific issue. Liu et al. (2017) indicated that fracture density has the greatest effect on the effective permeability that the increasing multiples can reach to 1 order of magnitude when matrix permeability is at $10^{-4} \mu \mathrm{m}^{2}$ level while fracture aperture has little effect. Mohsen et al. (2018) found that there is an abnormal trend of porosity-permeability in core data which is compatible with microfracture zones. Kumari et al. (2018) found that fracture propagation paths and apertures are mainly controlled by the stress state and the heterogeneity of the rock matrix in deep geothermal reservoirs. Sampath et al. (2019) found that $\mathrm{S}-\mathrm{CO}_{2}$ interaction causes new fracture formation and extension/widening of existing fractures in coal.

The heterogeneity of microfractures refers to the degree of heterogeneity in the length, width, geometry and extension direction of microfractures. It is necessary to study the heterogeneity of

E-mail address: dushuheng@imech.ac.cn. 
microfractures, which can reflect the complexity of the geological process related to reservoir formation and destruction, and then predict its impact on oil and gas accumulation, migration and seepage (Padin et al., 2014; Mokhtari and Azra, 2015; Pluymakers et al., 2017; Panahi et al., 2019). Therefore, we must quantify the heterogeneity of microfractures.

In previous studies, in order to characterize microfractures and micro-heterogeneity accurately, scholars have established parameters such as fracture width and fracture density (Williamsstroud et al., 2013; Karimpouli et al., 2017). Fracture density includes fracture linear density, surface density and volume density. The calculation of the width of microfracture mostly adopts the method of manual measurement. The casting slice of rock is made first, and then observed under polarizing microscope. The lengths and widths of microfractures are measured by drawing lines along the extension directions of the lengths and widths of microfractures, respectively, as the "lengths" and "widths" of microfractures. At the same time, many scholars have placed the probe slice under scanning electron microscopy for imaging, and carried out similar operations mentioned above (Blunt, 2001; Dong and Blunt, 2009; Williamsstroud et al., 2013; Liang, 2016; Karimpouli et al., 2017). This really enables us to grasp the development characteristics of microfractures to a certain extent. However, there are still two important problems left over:

(1) For unconventional reservoirs, there is still no strict mathematical definition of the lengths and widths of microfractures, and there is also no strict and clear formula for calculating the lengths and widths of microfractures.

(2) For unconventional reservoirs, the previous description of microfracture attributes is mostly confined to the description of microfracture size (length and width). Most scholars who pay attention to the geometry of microfractures use them to determine the formation causes of microfractures qualitatively, and distinguish them from structural, sedimentary or diagenetic ones. However, they did not conduct more in-depth quantitative criterion based on the microfracture geometry, nor did they establish more characterization parameters (Dick et al., 1994; Cardott et al., 2015; Ougier-Simonin et al., 2016; Panahi et al., 2019). So the attention of microfracture geometry quantification is slightly insufficient, and the characterizing parameters of microfracture geometry are also relatively few, resulting in the geological significance of microfracture geometry is not clear. Thus the formation mechanism of microfracture is not clear, too.

As to the deep tight reservoir, it is well known that the generation of microfractures is closely related to the value and direction of two horizontal principal stresses. When the difference between those two stresses is large, it is easy to form the unidirectional fracture zone; on the contrary, it is easy to form the multidirectional fracture zone (Mokhtari and Azra, 2015; Cardott et al., 2015; Pluymakers et al., 2017). But there is no quantitative parameters to carry out the division of the unidirectional and multidirectional fracture zone until now so as to the fracture mechanism has not been explored deeply which need to be pay attention to.

To sum up, there are at least four shortcomings in the study of microfractures in tight sandstone reservoirs at present which is as followings.

(1) There is still no accurate method for the quantitative calculation of the size and shape of microfractures. The previous methods are mostly confined to artificial and random measurement. So the accuracy and applicability need to be improved greatly.

(2) The possible mechanism of the formation of microfractures has not been discussed from the aspect of the fracture geometry, which is an extremely important factor.
(3) At present, the heterogeneity and anisotropy of the development of microfractures also lack quantitative characterization, and need to be further explored.

(4) There is no quantitative parameters to carry out the division of the unidirectional and multidirectional fracture zone so as to the facture mechanism has not been explored deeply.

Based on this, combined with core observation, high-resolution field emission electron microscopy imaging (FE-SEM) image processing, precise morphological analysis and new characterization parameters construction, we carry out the comprehensive quantitative characterization of microfractures developed in the tight oil reservoir of Ordos basin, clarify the possible formation mechanism and differences of microfractures. It would provide a new perspective and thinking for microfracture evaluation in unconventional oil and gas reservoirs.

\section{Geologic setting}

The Ordos Basin is located in the western portion of the North China landmass and the study area of Xin'anbian district is shown in Fig. 1. It is difficult to establish the effective displacement pressure system in the reservoir of the Upper Triassic Yanchang Formation because of the low permeability, the high original oil saturation (60\%-70\%), the complex reservoir pore connectivity, and the lithologic compactness (Du, 2019, Du et al., 2019).

The Shanbei slope has long maintained platform facies deposition, less structural activity, gentle stratigraphic occurrence, and undeveloped faults and folds. However, both core observation and field outcrop investigation show that fractures are widely developed in this area (Zeng et al., 2008; Lu et al., 2018).

The occurrence of fractures in this area is mostly vertical to the surface, and there is no obvious dislocation of fracture surface. Core observation shows that high angle fractures are widely developed, with a small number of oblique fractures. Generally speaking, the fractures of Chang-7 tight sandstone reservoir are mainly regional structural fractures, highangle fractures, with large area development, stable occurrence, and more developed ne fractures, which are characterized by high length, flat interface and nearly parallel distribution, which are the main fractures in the study area (Zeng et al., 2008; Lei et al., 2015). The results of tracer monitoring and interpretation show that there is a phenomenon of microfracture penetration in Yanchang reservoir, and water is easy to be seen in oil wells (Ding et al., 2016; Lu et al., 2018).

To sum up, characteristics and the formation mechanism of heterogeneous micro fracture need be furtherly discovered.

\section{Methods and results}

\subsection{Technical process}

Firstly, indoor observation of tight sandstone reservoir cores is carried out to identify the material base of microfracture development at core scale, so as to qualitatively understand the formation of microfracture.

Secondly, rock probe slices are made, the development degree and characteristics of microfractures are observed under the microscope with high-resolution field emission scanning electron microscopy (FESEM), so as to further understand the significance of microfractures as an important part of reservoir space.

Thirdly, a new characterization parameter of microfractures is constructed, which is endowed with clear geological significance. Attribute correlation analysis is carried out. Quantitative morphological characteristics and formation mechanism of microfractures are explored from a new perspective.

Finally, by synthetically evaluating the characteristics of microfracture development in a single view, new parameters are constructed, multi-directional fracture zone and unidirectional fracture zone are 


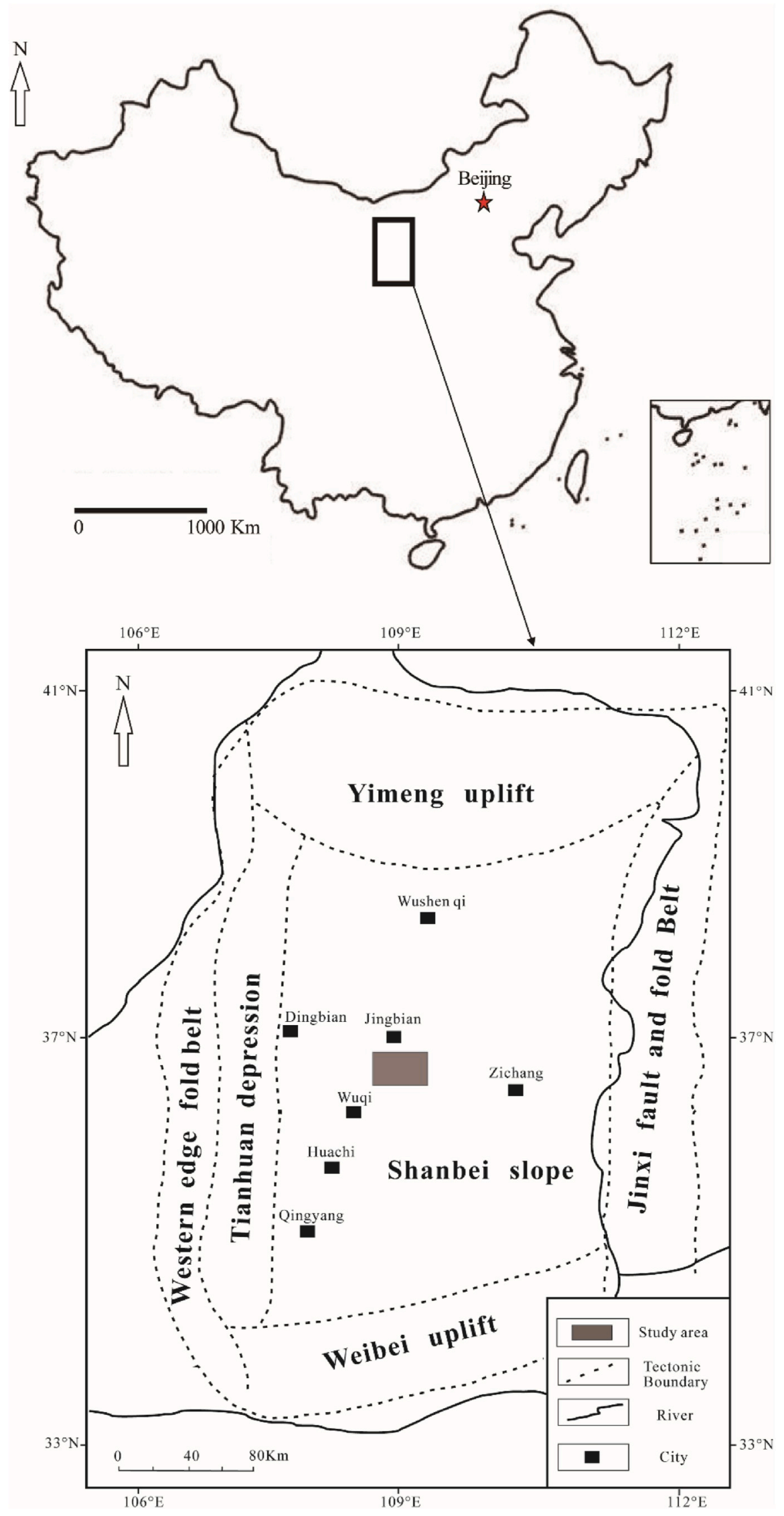

Fig. 1. The location of study area in Ordos Basin, China (Du, 2019, Du et al., 2019). 
defined, and their judgment rule is given. Quantitative differences in average length and width of microfracture between the two microfracture development zones are calculated quantitatively.

\subsection{Core observation results}

By observing the core of the tight oil reservoir of Yanchang member in Ordos Basin (Fig. 2), it is found that the lithology is mainly greywhite, grey-green medium-slender feldspar sandstone, which contains lithic feldspar sandstone and feldspathic lithic sandstone with low component maturity.

Among them, the development of bedding fracture is common. Residual oil is enriched along the fracture development location. In reservoir hydraulic fracturing, it is easy to connect with the artificial fracture to form more complex seepage channels.

\subsection{High resolution field emission-scanning electron microscope imaging}

High-resolution FE-SEM images of reservoirs show that microfractures are widely developed (Fig. 3). The development of microfractures presents two characteristics: singularity and diversity. The development of microfractures not only follows the dominant direction of pores, but also cuts through minerals. Therefore, how to describe the characteristics of these microfractures perfectly and quantitatively requires us to innovate our thinking.

Most of the microfractures are located in brittle minerals (feldspar, quartz, calcite, etc.). In Fig. 4, it can be seen that some minerals did not have straight fracture trajectories and large curvatures (Fig. 4-a, b and e), and some minerals have relatively straight extension patterns of microfractures, which belong to the fracture along the direction of cleavage fracture (Fig. 4-c, d and f), reflecting the heterogeneity of microfracture development in single minerals. It is the fracture heterogeneity of single mineral that results in the overall heterogeneity of microfractures.

\subsection{Construction of morphological characterization parameters of microfractures}

In order to better clarify the development characteristics and formation mechanism of microfractures, this paper defines two sets of parameters describing the size of microfractures from the perspective of computational geometry, combined with Feret diameter calculation and Legendre ellipse fitting, we calculates the maximum Feret diameter of microfracture, defines it as the length of microfracture, then calculates the minimum Feret diameter of microfracture and defines it as the width of microfracture. At the same time, as the shape of microfractures is irregular, in order to characterize the size of microfractures more objectively, we define the lengths of major axis and minor axis of
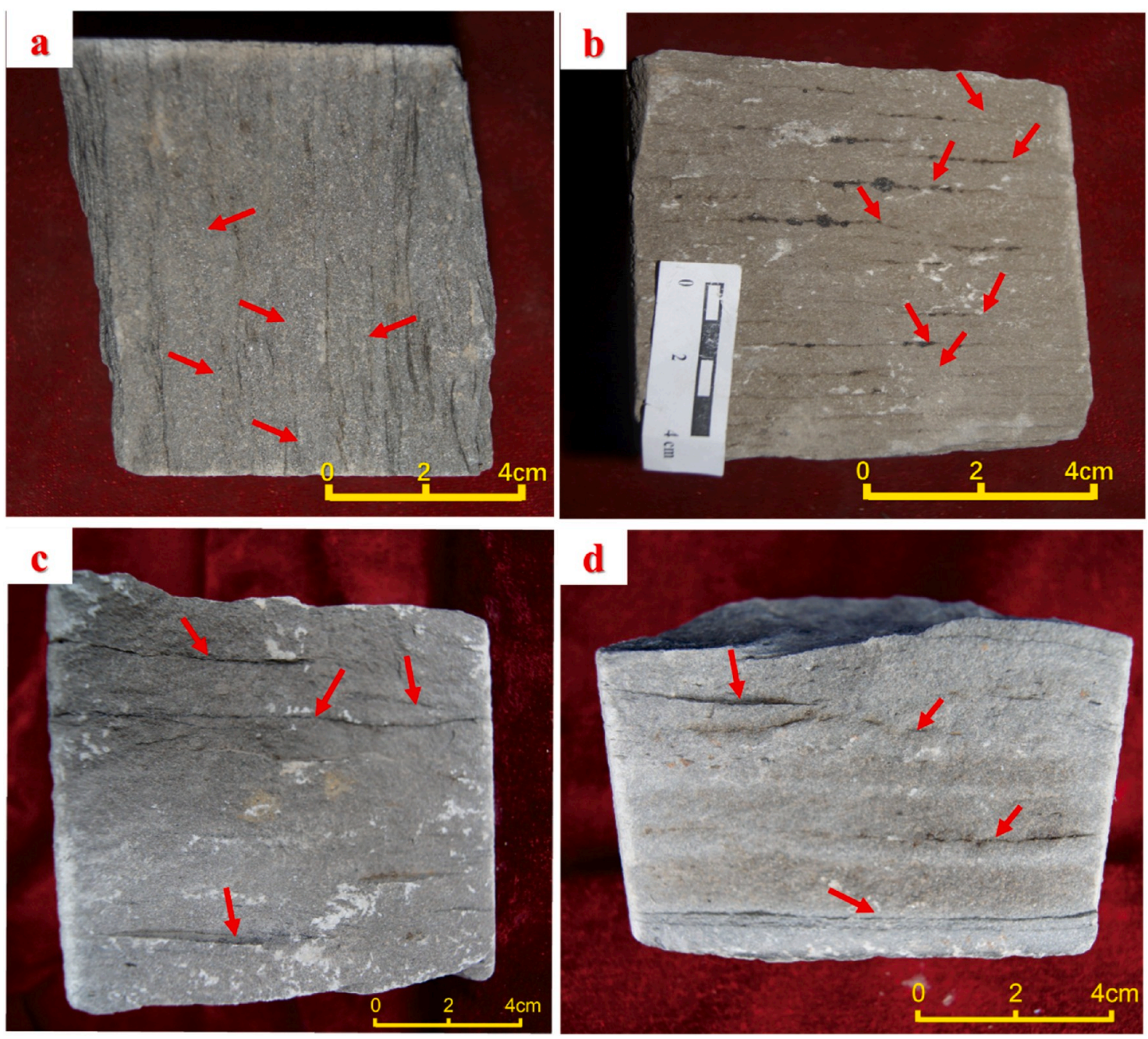

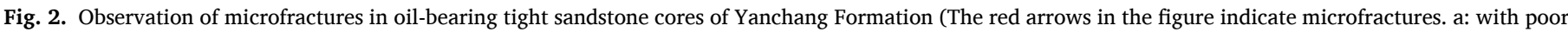

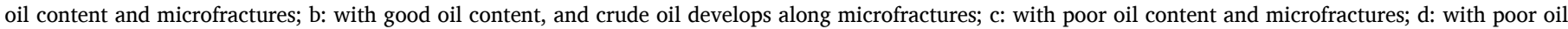

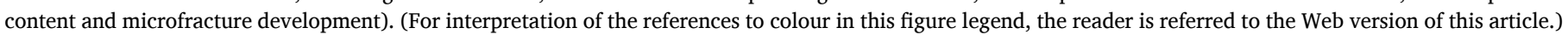



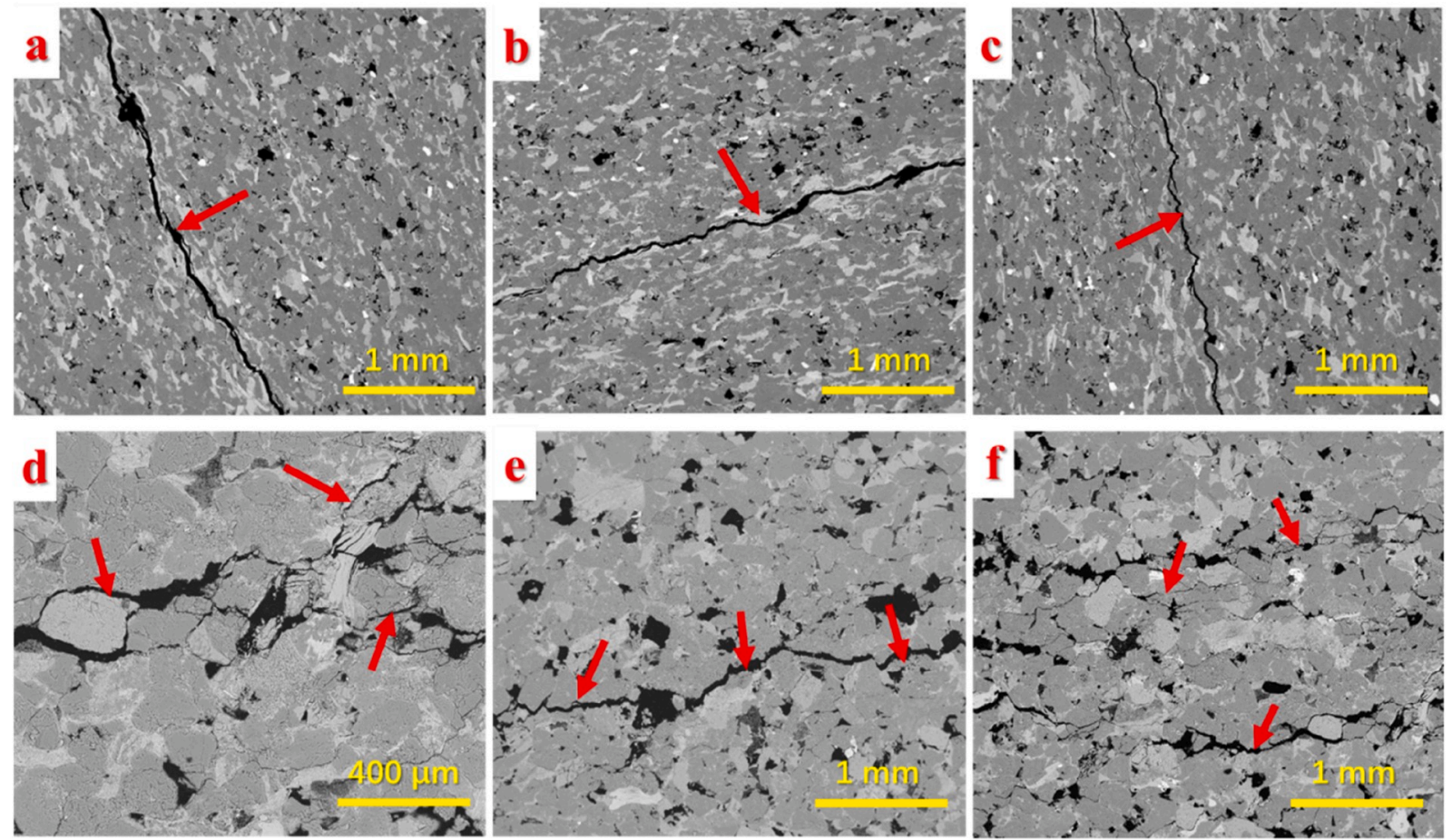

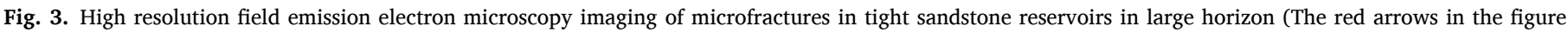
indicate microfractures. a, b, c: well "B", Yanchang formation; d, e, f: well "A", Yanchang formation). (For interpretation of the references to colour in this figure legend, the reader is referred to the Web version of this article.)
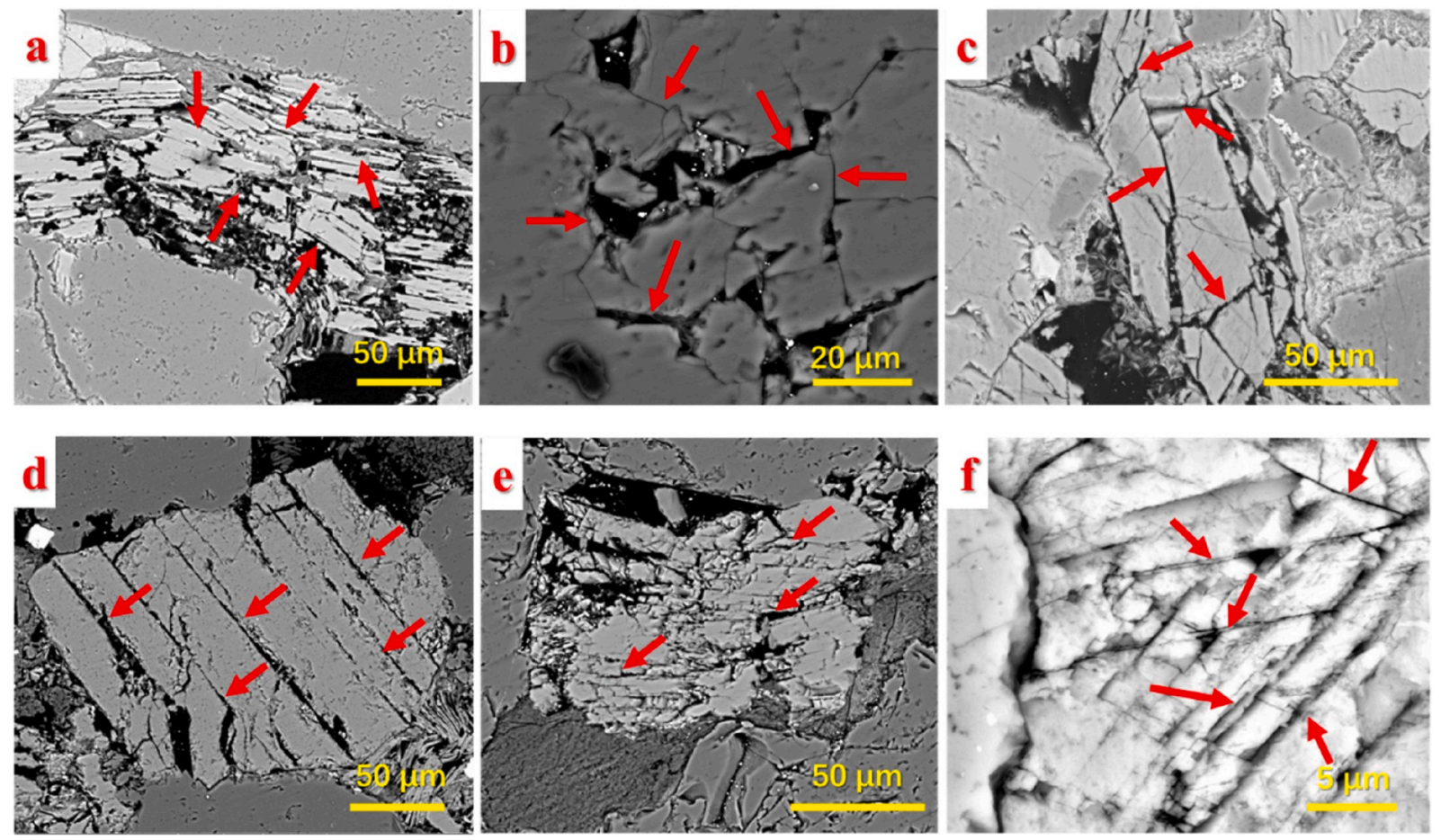

Fig. 4. High resolution field emission electron microscopy imaging of microfractures in tight sandstone reservoirs at mineral scale (The red arrows in the figure indicate microfractures. a, b: well "B",; c: well "C",; d, e, f: well "A"). (For interpretation of the references to colour in this figure legend, the reader is referred to the Web version of this article.)

microfractures ellipse, which can help us describe the size characteristics of microfractures more comprehensively and avoid making too absolute judgments.

The calculation method of Legendre elliptic equation of micro- fractures is as follows (Mikli et al., 2001; Pirard, 2004): firstly, the shape coordinates of microfractures are obtained by image processing, and the true inertia moment of microfractures and their surrounding areas is obtained. Then, ellipses with the same inertial characteristics are 
deduced by using these data through mathematical method. The main calculation principle is as follows:

a) Measure the inertia moment of the shape coordinates (Equations (1)(3)).

$\sigma_{x x}=\frac{1}{n} \sum\left(x_{i}-\bar{x}\right)^{2}$

$\sigma_{y y}=\frac{1}{n} \sum\left(y_{i}-\bar{y}\right)^{2}$

$\sigma_{x y}=\frac{1}{n} \sum\left(y_{i}-\bar{y}\right)\left(x_{i}-x\right)$

In order to calculate the length of major axis and minor axis of Legendre ellipse, we have made the following provisions:

$\alpha=\frac{1}{2}\left(\sigma_{x x}+\sigma_{y y}\right)$

$\beta=\sqrt{\alpha^{2}-\sigma_{x x} \sigma_{y y}+\sigma_{x y}}$

b) Substitute formulas (4) and (5) into (6) and (7) to calculate the length of the major and minor axes of Legendre ellipse.

$\alpha_{\text {major }}=4 \sqrt{\alpha+\beta}$

$\alpha_{\text {minor }}=4 \sqrt{\alpha-\beta}$

It should be pointed out that, the maximum and minimum of Feret's diameter indicates the longest and shortest distance between any two points along the fracture boundary. Legendre's inertial ellipse is obtained by fitting the shape of the microfracture. The center of the ellipse is located at the center of the microfracture, and it has the same geometric moment, even the second moment, as the original area of the microfracture.

When we talk about the geometry characterization of microfracture, it is reasonable to assume that the overall concavity of the pores should be high in the reservoir with strong compaction. As to pores, the average degrees of concave and convex can be used as indicative parameters of reservoir compaction. Analogous to "particle solidity," the new parameter of "solidity of microfracture" is introduced in this paper (Fig. 5). "Solidity of microfracture" could be used to characterize the concave and convex degrees of microfractures.

In addition, we also define a new parameter to describe the degree of microfracture boundary tortuosity, which is calculated by dividing the actual circumference of microfracture boundary by the elliptical circumference of microfracture. We call it "new tortuosity" in order to distinguish it from the traditional concept of tortuosity (Fig. 5). It can be seen that the greater the new tortuosity, the more uneven the boundary of microfractures.

In order to illustrate the relationship between the solidity and the compaction degree of microfractures in tight sandstone reservoirs more directly, the sketch map was given (Fig. 6). Obviously, the smaller the solidity of microfracture, the higher the degree of compaction. Of course, the rationality of this parameter still needs to be tested and improved in practice.This will be a potential scientific issue.

However, the smoothness of the boundary of microfractures mainly depends on the intensity of dissolution, which may be caused by the invasion and dissolution of geological fluids, or by the compaction again after the formation of microfractures, resulting in pressure dissolution. The microfractures formed by pure tectonism are mainly based on brittle minerals. Their fracture edges are generally flat. If they are transformed by sedimentary diagenesis (mainly dissolution), the edges of microfractures will become curved. The stronger the dissolution, the higher the bending degree. The new tortuosity can well reflect this kind of tortuosity, so it can be used as one of the important parameters of reflecting the dissolution. But frankly, the mechanism still deserves further discussion.

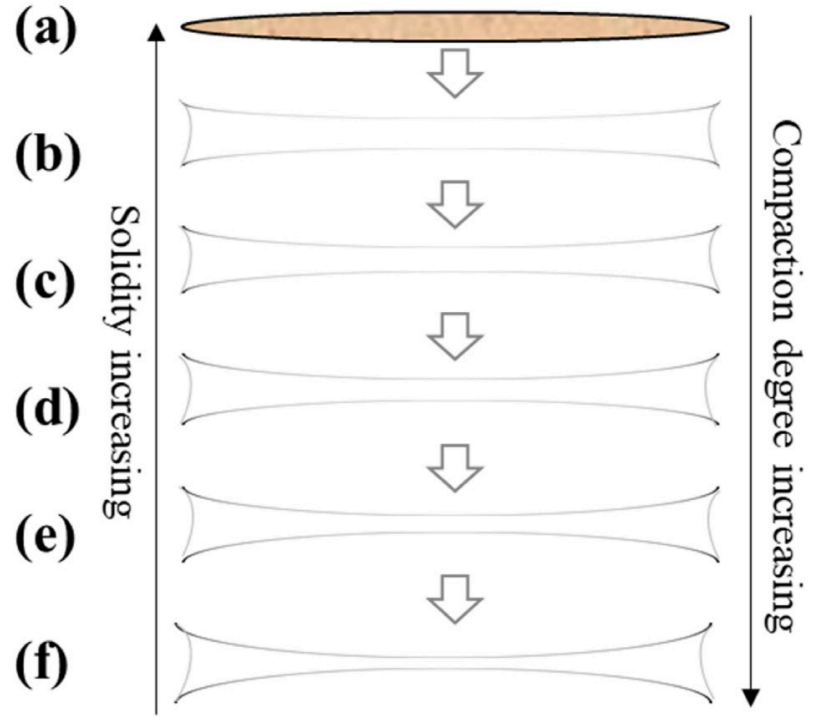

Fig. 6. Relationship between the solidity and the compaction degree of microfractures in tight sandstone reservoirs.
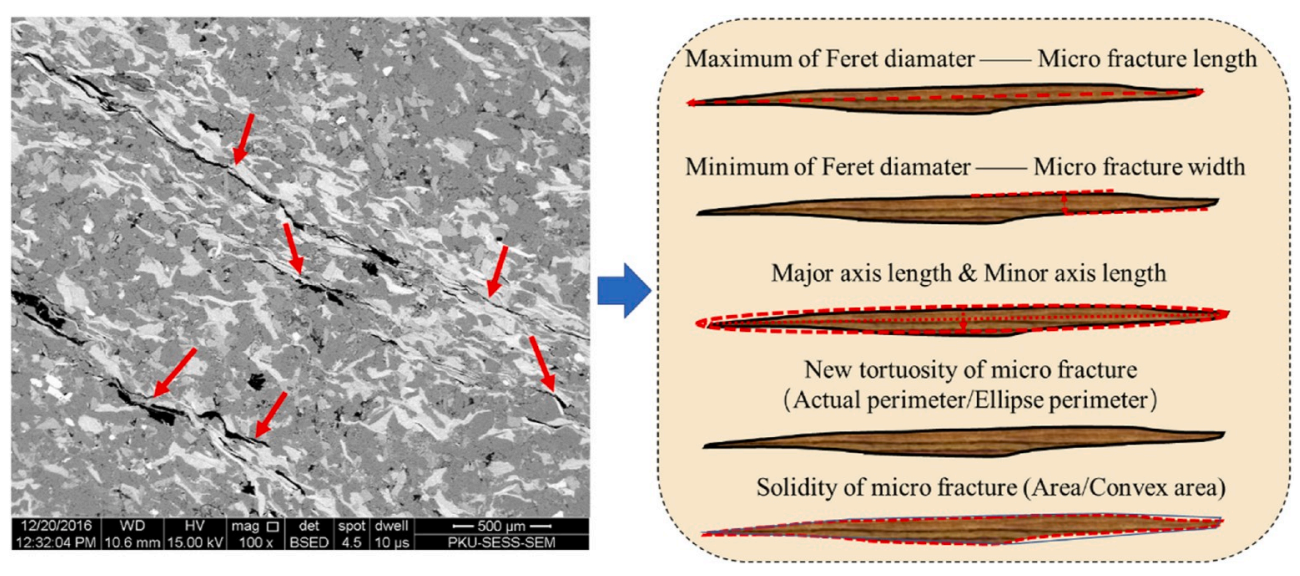

Fig. 5. Construction of new parameters for accurate characterization of microfractures in tight sandstone reservoirs (The red arrows in the figure indicate microfractures.). (For interpretation of the references to colour in this figure legend, the reader is referred to the Web version of this article.) 


\section{Discussion}

\subsection{Properties relationships in microfractures}

\subsubsection{Relationship between the maximum Feret diameter (length) and the} minimum Feret diameter (width) of microfractures

In order to analyze the relationship between the maximum Feret diameter (length) and the minimum Feret diameter (width) of microfractures, 459 microfractures were chosen from 70 samples. We extract 459 microfractures from 70 samples of tight oil reservoir by fine image processing. According to the calculation principle of Feret diameter, we write the relative program for the calculation of the length and width of microfractures, and calculate the maximum and minimum Feret diameter of 459 microfractures. At the same time, we calculated the standard deviation of the length and width of microfractures in 70 samples. At last, we draw the cross-plot which can be seen in Figs. 7 and 8 .

In Fig. 7, it can be seen that the length and width of microfractures are positively correlated as a whole, but the distribution of data presents an interesting phenomenon, showing a significant phenomenon of zoning. When the lengths of microfractures are less than $600 \mu \mathrm{m}$ (corresponding to the widths of microfractures are less than $90 \mu \mathrm{m}$ ), they show a good linear positive correlation, but when the lengths of microfractures continue to increase, the widths of microfractures begin to deviate from the linear relationship and gradually diverges.

Each data point in Fig. 7 represents the average of the length and width of the microfractures. Therefore, in order to study the fluctuation characteristics (data standard deviation) of the length and width values of all microfractures and their relationships, we have calculated the standard deviation of the length and width values of all microfractures and made their cross-plot diagrams (Fig. 8).

From Fig. 8, we can also see that, in general, the greater the fluctuation degree of microfracture length value, the greater the fluctuation degree of width value. However, with the increasing fluctuation of the length of microfractures, the data are also constantly divergent, which is related to the instability of the formation of microfractures mentioned above.

\subsubsection{Relationship between Legendre ellipse length and width of} microfractures

Similarly, In order to analyze the relationship between Legendre ellipse length and width of microfractures, 459 microfractures were chosen from 70 samples. We extract 459 microfractures from 70 samples

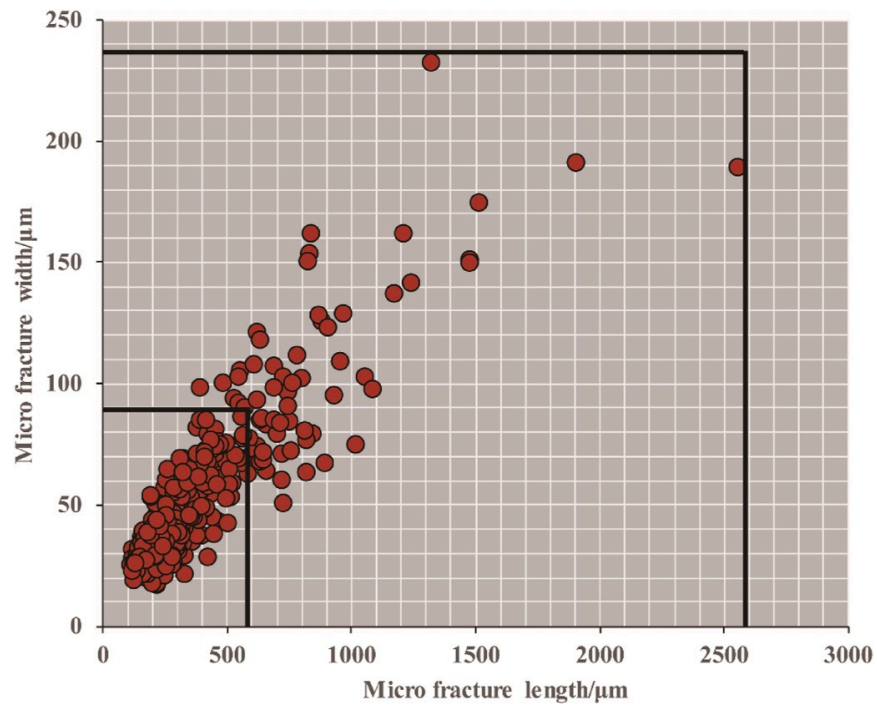

Fig. 7. Cross-plot of microfracture length and microfracture width in tight sandstone reservoir.

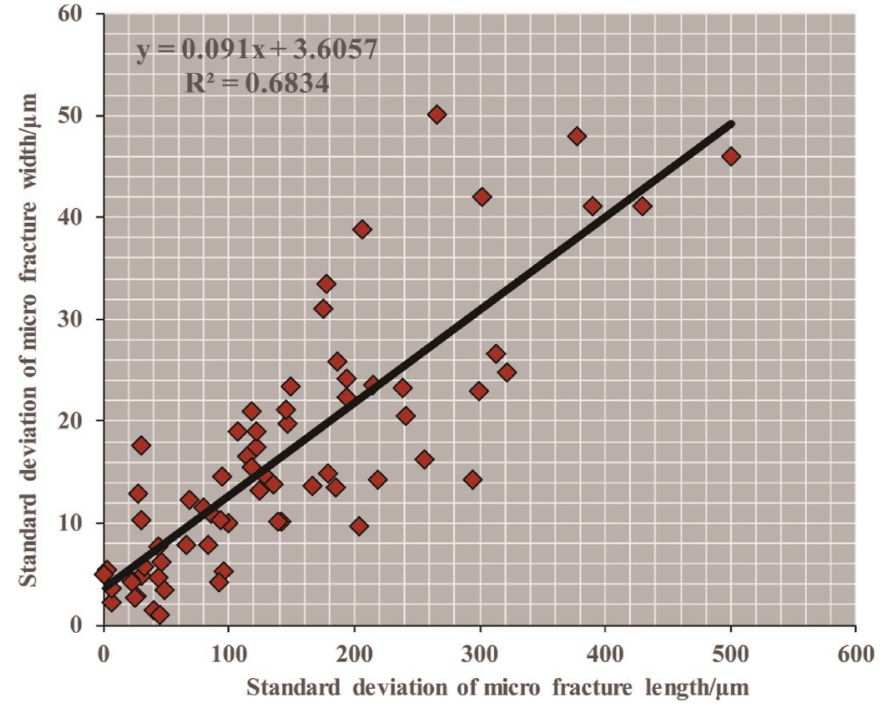

Fig. 8. Standard deviation cross-plot of microfracture length value and microfracture width value in tight sandstone reservoir.

of tight oil reservoir by fine image processing. According to the calculation principle of Legendre ellipse, we write the relative program for the calculation of Legendre ellipse length and width of microfractures, and calculate the Legendre ellipse length and width of 459 microfractures. At the same time, we calculated the standard deviation of the Legendre ellipse length and width of microfractures in 70 samples. At last, we draw the cross-plot which can be seen in Figs. 9 and 10.

The Legendre ellipse of each microfracture is fitted, and the lengths of the long axis and the minor axis of each microfracture are calculated respectively. These two length values are used as supplementary parameters to describe the size characteristics of microfractures (Figs. 9-10).

It can be seen that when the major axis value of the ellipse is less than $400 \mu \mathrm{m}$ (corresponding to the minor axis value of the ellipse is less than $44 \mu \mathrm{m}$ ), they show a good linear positive correlation, but when the long axis value of the ellipse continues to increase, the width of the microfracture gradually deviates from the linear relationship and gradually diverges.

Similarly, the greater the fluctuation degree of the long axis value of

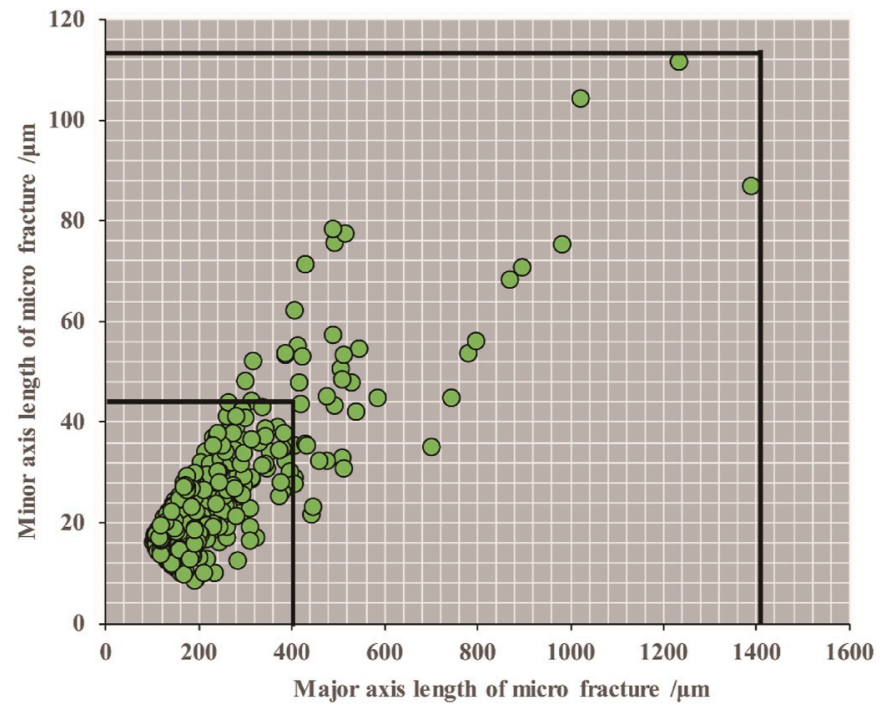

Fig. 9. Cross-plot of standard deviation of the major and minor axis value of microfracture in tight sandstone reservoir. 


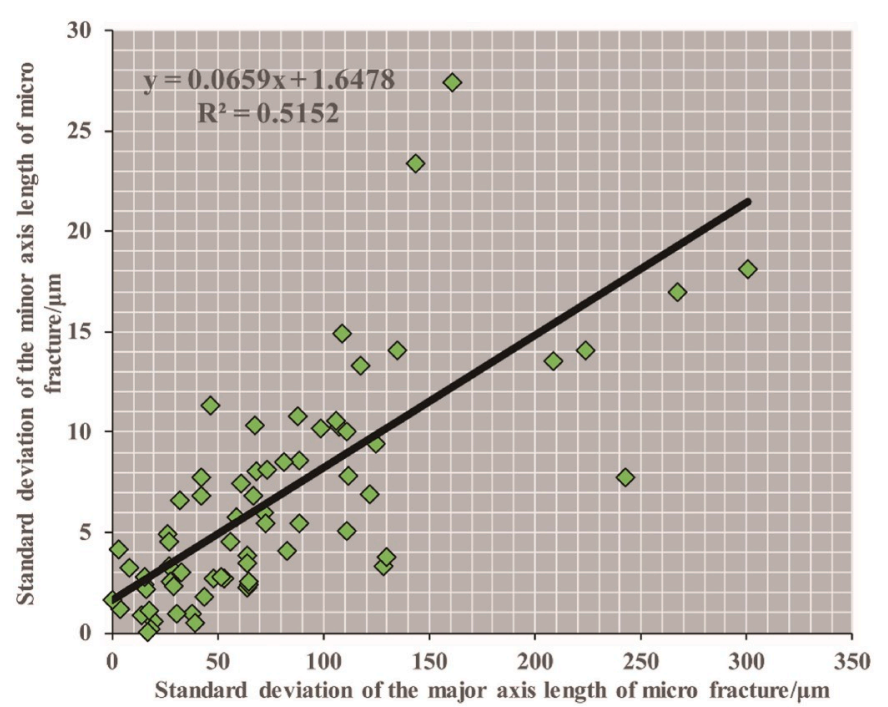

Fig. 10. Intersection diagram of standard deviation and minor axis value of microfracture in tight sandstone reservoir.

an ellipse, the greater the fluctuation degree of the minor axis value of an ellipse. However, as the fluctuation of elliptical long axis value increases, the data begin to diverge. This also proves the conclusion of 4.1.1 very well.

\subsubsection{Relationship between the solidity and the new tortuosity of microfractures}

Similarly, in order to analyze the relationship between the solidity and the new tortuosity of microfractures.

In order to explore the relationship between the degree of compaction and the degree of dissolution of microfractures, the correlation regression between the solidity of microfractures and the new tortuosity of microfractures is made (Fig. 11).

The results are also interesting. With the power exponential increase of compression degree (i.e. the solidity value of microfractures gradually decreases), the new tortuosity value of microfractures gradually increases, and the rate of increase gradually increases (Fig. 11).

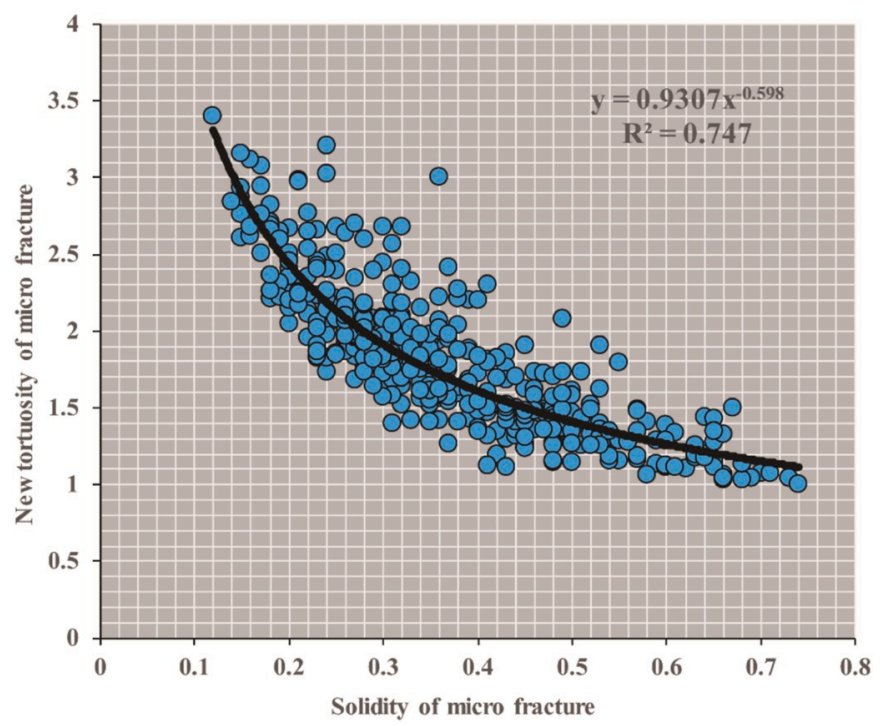

Fig. 11. Cross-plot of microfracture solidity and new tortuosity of microfracture in tight sandstone reservoir.

\subsection{Characteristics and significance of multidirectional fracture zone and unidirectional fracture zone}

From the electron microscopic observation of microfractures, we can find that in some horizons, the development of microfractures presents unidirectional distribution, that is, all microfractures rupture and extend in the same direction. We define them as unidirectional fracture zone (Fig. 12). However, in some horizons, microfractures are fractured along different directions, and there is no significant extension direction. We define it as multi-directional fracture zone (Fig. 13). It is difficult for us to scientifically distinguish these two types of zones by naked eyes alone. Therefore, we try to solve this problem from the angle of microfracture extension.

The length, width, geometry shape, extension angle of microfractures in the two regions are calculated and compared to distinguish the multi-directional fracture zone from the unidirectional fracture zone. Table 1 shows that the average length of microfractures in unidirectional fracture zone is higher than which in multidirectional fracture zone, which is also in line with common sense. Unidirectional fractures can extend unidirectionally, but multidirectional fractures are mutually controlled, and it is impossible to form too long fractures.

As far as the homogeneity coefficient is concerned, we divide the maximum value by the average value to get this parameter. The larger the homogeneity coefficient is, the more homogeneous the distribution pattern of data is. We can see that the homogeneity of unidirectional fracture zone is higher than which of multidirectional fracture zone, which is easy to understand.

As far as the ratio of maximum value to minimum value is concerned, unidirectional fracture zone is higher than multidirectional fracture zone. This is also related to the mineral type content of reservoir.

\subsection{Summary of the formation mechanism}

As to microfractures, length and width, the major and minor axis of fitted ellipses, the solidity and the new tortuosity are all the properties of microfractures. We study the formation mechanism of micro fractures mainly through the quantitative characterization and correlation analysis of these characteristic attributes to explore the possible mechanism of the formation of micro fractures, which is in line with the basic view of "discussing the present and the ancient" in geological research. The in-depth analysis and discussion of the correlation of the micro fracture attribute parameters, including the relationship between length and width of microfractures, Legendre ellipse length and width of microfractures, solidity and the new tortuosity of microfractures were all carried out.

The above study indicates that the length (major axis value) and width (minor axis value) of microfractures are not strictly and steadily correlated, but have a certain threshold value. If the lengths of microfractures increase due to the change of internal or external stress, when the length (major axis value) value is higher than a certain value, the opening process of microfractures will begin to lose stability, and the width (minor axis value)will change gradually irregularly (Figs. 7 and 9). This could also be proved by the standard deviation cross-plot of microfracture length value (major axis value) and microfracture width value (minor axis value) in tight sandstone reservoir (Figs. 8 and 10). This fully shows that the formation process of microfractures is a transition from steady state to unsteady state. The microfractures are in the stage of steady-state propagation from initiation to opening. In the steady-state stage, the length and width of microfractures show a good positive linear correlation, which indicates that the microfractures are expanding in a positive steady-state state. However, when the microfractures expand to a certain extent, due to the limitations of internal factors (including mineral, pore distribution, fluid and other factors) and external factors (in-situ stress changes), the regularity of the length and width of microfractures is destroyed, the microfractures are unstable and microfractures are broken. It is an important mechanism for the 

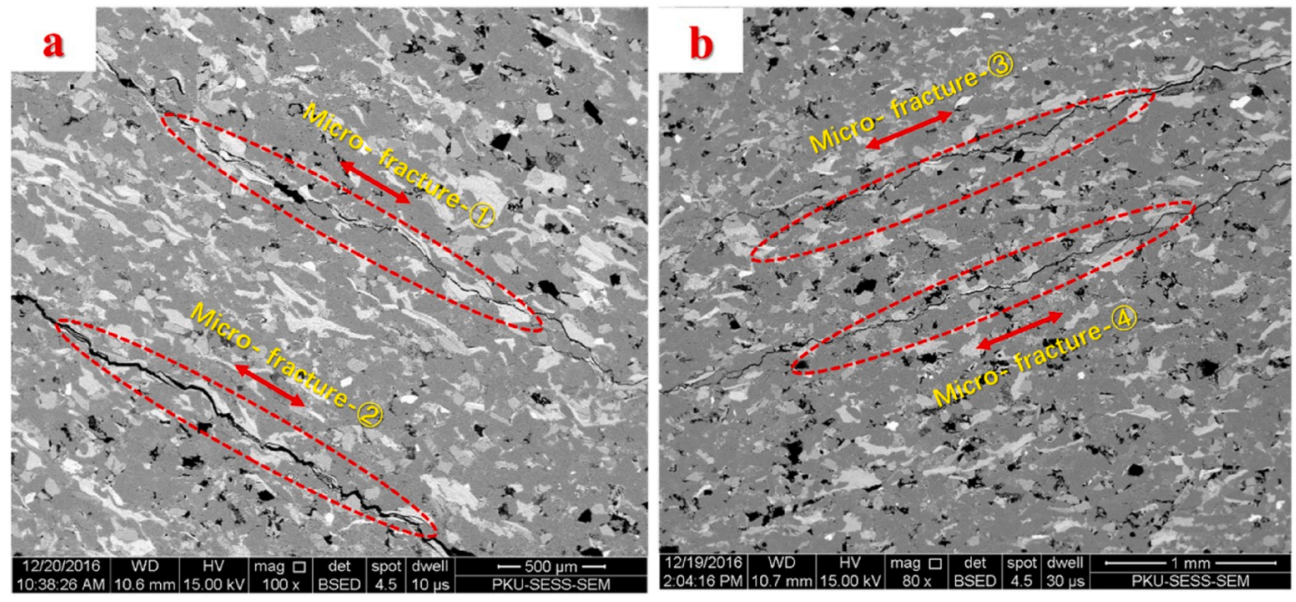

Fig. 12. Identification of fracture zones in tight sandstone reservoirs.
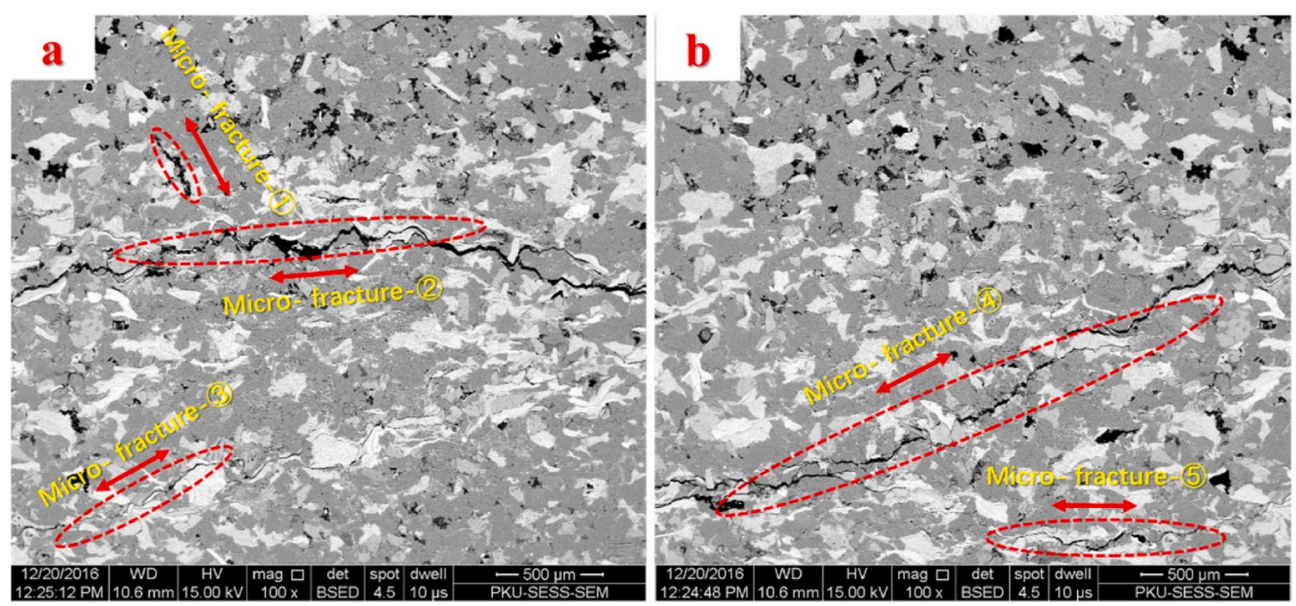

Fig. 13. Identification of multidirectional fracture zones in tight sandstone reservoirs.

Table 1

Comparison of average length and width of microfractures between multidirectional and unidirectional fracture zones in tight sandstone reservoirs.

\begin{tabular}{|c|c|c|c|}
\hline Data properties & $\begin{array}{c}\text { Fracture } \\
\text { characteristics }\end{array}$ & $\begin{array}{c}\text { Micro fracture } \\
\text { length/ } \mu \mathrm{m}\end{array}$ & $\begin{array}{c}\text { Micro fracture } \\
\text { width/ } / \mu \mathrm{m}\end{array}$ \\
\hline \multirow{2}{*}{ Average } & $\begin{array}{l}\text { Multidirectional } \\
\text { fracture zone }\end{array}$ & 297.89 & 44.34 \\
\hline & $\begin{array}{l}\text { Unidirectional } \\
\text { fracture zone }\end{array}$ & 359.61 & 51.49 \\
\hline \multirow{2}{*}{$\begin{array}{l}\text { Homogeneity } \\
\text { coefficient }\end{array}$} & $\begin{array}{l}\text { Multidirectional } \\
\text { fracture zone }\end{array}$ & 0.55 & 0.69 \\
\hline & $\begin{array}{l}\text { Unidirectional } \\
\text { fracture zone }\end{array}$ & 0.45 & 0.45 \\
\hline \multirow{2}{*}{$\begin{array}{l}\text { Ratio between } \\
\text { maximum and } \\
\text { minimum }\end{array}$} & $\begin{array}{l}\text { Multidirectional } \\
\text { fracture zone }\end{array}$ & 3.05 & 2.28 \\
\hline & $\begin{array}{l}\text { Unidirectional } \\
\text { fracture zone }\end{array}$ & 4.41 & 3.91 \\
\hline
\end{tabular}

formation of microfractures.

The Cross-plot of microfracture solidity and new tortuosity of microfracture in tight sandstone reservoir also proves that compaction will have a more important impact on dissolution. It is reasonable to infer that once the compaction reach a certain extent. Some of the previously opened microfractures will be temporarily closed, which will greatly promote the process of pressure dissolution, and thus increase the microfracture tortuosity.
In addition, as the microfracture distribution, in order to figure out the formation mechanism of the unidirectional fracture zone to multidirectional fracture zone, we should find the transformation criterion. Actually, if we can calculate the extension angle of all microfractures in a certain area, and then calculate the standard deviation of all angle values in the field of view, we call it multidirectional fracture index, which can quantitatively characterize the fluctuation degree of microfracture angle in a field of view (Fig. 14).

It is easy to know that if the angle fluctuation of microfracture is small, it is considered that the fracture in this area extends in the same direction; on the contrary, it is considered that the fracture extends in many directions. So is there a key point for segmentation? We make a statistical histogram of the standard deviation of the angle values of all the microfractures. We can clearly see that there is a very special data point (multi-directional fracture index value is 15.042). When it is lower than this point, the index of multidirectional fracture increases slowly. When it is higher than this point, the index increases in a steep-slope hurricane. We could easily judge that this point is the turning point from unidirectional fracture zone to multidirectional fracture zone.

\section{Conclusions}

As to the micro-facture in the tight oil sandstone reservoir, when the lengths of microfractures are less than $600 \mu \mathrm{m}$ (corresponding to the widths of microfractures are less than $90 \mu \mathrm{m}$ ), they show a good linear positive correlation, but when the lengths of microfractures continue to 


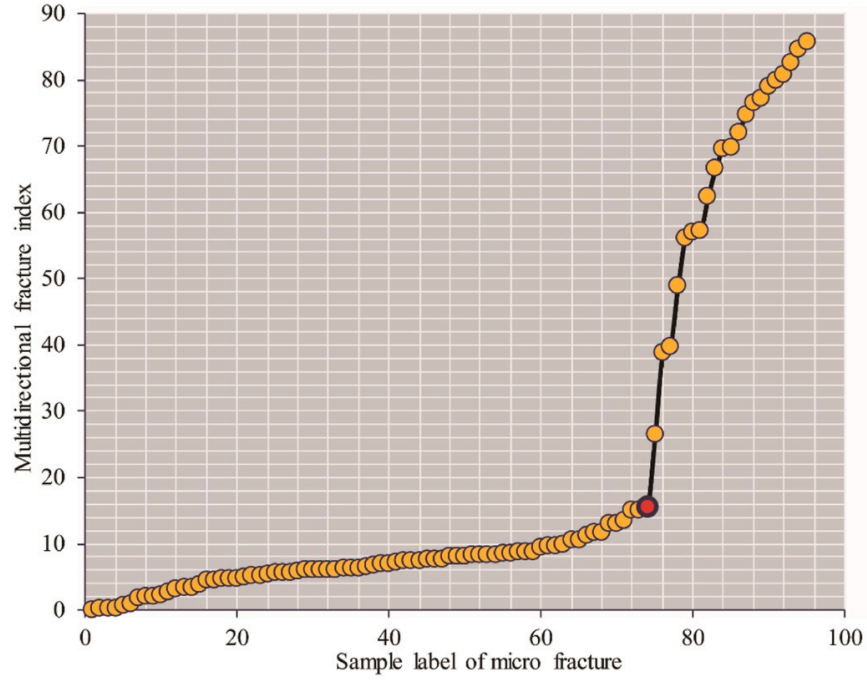

Fig. 14. Statistical histogram of multidirectional fracture index for tight sandstone reservoirs (All data are all from Yanchang formation).

increase, the widths of microfractures begin toy deviate from the linear relationship and gradually diverges. This indicates that the lengths and widths of microfractures are not strictly and steadily correlated, but have a certain threshold value. If the lengths of microfractures increase due to the change of internal or external stress, when the length value is higher than a certain value, the opening process of microfractures will begin to lose stability, and the widths will change gradually irregularly. Relationship between Legendre ellipse lengths and widths of microfractures, relationship between the solidity and the new tortuosity of microfractures could both be the important evidences to prove the above conclusion.

It should be noted that the heterogeneity and anisotropy of the development of microfractures in tight oil reservoirs lack the quantitative characterization, and the formation of the microfracture need to be furtherly explored in other aspects in the coming days.

\section{Declaration of competing interest}

The authors declare that they have no known competing financial interests or personal relationships that could have appeared to influence the work reported in this paper.

\section{Acknowledgements}

This work was jointly supported by National Natural Science Foundation of China (NSFC, Grant No.41902132, 11872363, 51861145314), Open Fund of Key Laboratory of Oil and Gas Resources Research (Grant No. KLOR2018-6), Chinese Academy of Sciences, Chinese Academy of Sciences (CAS) through the CAS Key Research Program of Frontier Sciences (Grant No. QYZDJ-SSW-JSC019), the CAS Strategic Priority Research Program (Grant No. XDB22040401) and Open Fund (Grant No. PLC20190401) of State Key Laboratory of Oil and Gas Reservoir Geology and Exploitation (Chengdu University of Technology).

\section{References}

Blunt, M., 2001. Flow in porous media-pore-network models and multiphase flow. Curr. Opin. Colloid Interface Sci. 6 (3), 197-207.

Cardott, Brian J., Landis, Charles R., Curtis, Mark E., 2015. Post-oil solid bitumen network in the Woodford Shale, USA — a potential primary migration pathway. Int. J. Coal Geol. 139, 106-113.

Dai, C., Liu, H., Wang, Y., Li, X., Wang, W., 2019. A simulation approach for shale gas development in China with embedded discrete fracture modeling. Mar. Petrol. Geol. 100, 519-529.
Dick, Jeffrey C., Abdul, Shakoor, Wells, Neil, 1994. A geological approach toward developing a mud rock-durability classification system. Can. Geotech. J. 31 (1), 17-27.

Ding, W., Dai, P., Zhu, D., Zhang, Y., He, J., Li, A., Wang, R., 2016. Fractures in continental shale reservoirs: a case study of the Upper Triassic strata in the SE Ordos Basin, Central China. Geol. Mag. 153 (4), 663-680.

Dong, H., Blunt, M., 2009. Pore-network extraction from micro-computerizedtomography images. Phys. Rev. E - Stat. Nonlinear Soft Matter Phys. 80 (3 Pt 2), 036307.

Du, S.H., 2019. Prediction of permeability and its anisotropy of tight oil reservoir via precise pore-throat tortuosity characterization and "umbrella deconstruction" method. J. Petrol. Sci. Eng. 178, 1018-1028.

Du, S., Shi, Y.M., Bu, X.Q., Jin, W.Q., Mu, G.Q., 2015. New expression of the changing stress field in low-permeability reservoir and its application in secondary exploitation. Energy Explor. Exploit. 33 (4), 491-514.

Du, S., Shi, Y.M., Guan, P., Zhang, Y.G., 2016. New inspiration on effective development of tight reservoir in secondary exploitation by using rock mechanics method. Energy Explor. Exploit. 34 (1), 3-18.

Du, S.H., Pang, S., Shi, Y.M., 2018a. A new and more precise experiment method for characterizing the mineralogical heterogeneity of unconventional hydrocarbon reservoirs. Fuel 232, 666-671.

Du, S.H., Pang, S., Shi, Y.M., 2018b. Quantitative characterization on the microscopic pore heterogeneity of tight sandstone reservoir by considering both the resolution and representativeness. J. Petrol. Sci. Eng. 169, 388-392.

Du, S.H., Shi, G.X., Yue, X.J., Kou, G., Zhou, B., Shi, Y.M., 2019. Imaging-based characterization of perthite in the upper triassic Yanchang formation tight sandstone of the Ordos Basin, China. Acta Geol. Sin. Engl. Ed. 93 (2), 373-385.

Mohsen, Ezati, Azizzadeh, Mehran, Riahi, Mohammad Ali, Fattahpour, Vahidoddin, Honarmand, Javad, 2018. Characterization of microfractures in carbonate Sarvak reservoir, using petrophysical and geological data, SW Iran. J. Petrol. Sci. Eng. 170, 675-695.

Du, S.H., Shi, Y.M, Zheng, X.J., Chai, G.S., 2020. Using "Umbrella Deconstruction \& Energy Dispersive Spectrometer (UD-EDS)" technique to quantify the anisotropic elements distribution of "Chang 7" shale and its significance. Energy 191. https:// doi.org/10.1016/j.energy.2019.116443.

Ge, X.M., Fan, Y.R., Li, J.T., Muhammad, A.Z., 2015. Pore structure characterization and classification using multifractal theory- an application in tight reservoir of Santanghu basin in Western China. J. Petrol. Sci. Eng. 127, 297-304.

Karimpouli, S., Tahmasebi, P., Ramandi, H., et al., 2017. Stochastic modeling of coal fracture network by direct use of micro-computed tomography images. Int. J. Coal Geol. 179.

Kumari, W.G.P., Ranjith, P.G., Perera, M.S.A., Li, X., Li, L.H., Chen, B.K., Avanthi Isaka, B.L., De Silva, V.R.S., 2018. Hydraulic fracturing under high temperature and pressure conditions with micro CT applications: geothermal energy from hot dry rocks. Fuel 230, 138-154.

Lei, Y., Luo, X., Wang, X., Zhang, L., Jiang, C., Yang, W., Zhang, L., 2015. Characteristics of silty laminae in Zhangjiatan Shale of southeastern Ordos Basin, China: implications for shale gas formation. AAPG (Am. Assoc. Pet. Geol.) Bull. 99 (4), 661-687.

Liang, Y., 2016. Rock fracture skeleton tracing by image processing and quantitative analysis by geometry features. J. Geophys. Eng. 13 (3), 273-284.

Liu, L.J., Yao, Y., Zhang, L., An, S.Y., Zhao, J.L., Sun, H., 2017. REV-scale simulation of microfractured unconventional gas reservoir. J. Nat. Gas Sci. Eng. 48, 100-110.

Lu, X.W., Du, S.H., Zheng, K., Zhang, H.G., Sun, T., Wang, H., 2018. Fracture development characteristics in tight sandstone oil reservoir and its inspiration on remaining oil recovery: a case study on the chang- $7_{2}^{2}$ layer of Yanchang formation in Xin'anbian area, Ordos Basin. Acta Sci. Nauralium Univ. Pekin. 54 (1), 42-48.

Mikli, V., Käerdi, H., Kulu, P., Besterci, M., 2001. Characterization of powder particle morphology. Proc. Est. Acad. Sci. Eng. 722 (1), 22-34.

Mokhtari, M., Azra, N.T., 2015. Characterization of anisotropy in the permeability of organic-rich shales. J. Petrol. Sci. Eng. 133, 496-506.

Ougier-Simonin, A., Renard, F., Boehm, C., Vidal-Gilbert, S., 2016. Microfracturing and microporosity in shales. Earth Sci. Rev. 162, 198-226.

Padin, Anton, Tutuncu, Azra N., Steve, Sonnenberg, 2014. On the mechanisms of shale microfracture propagation. In: SPE Hydraulic Fracturing Technology Conference. Society of Petroleum Engineers.

Panahi, H., Kobchenko, M., Meakin, P., Dysthe, D.K., Renard, F., 2019. Fluid expulsion and microfracturing during the pyrolysis of an organic rich shale. Fuel 235, 1-16.

Pirard, E., 2004. Image measurements (Chapter 4). In: Francus, P. (Ed.), Image Analysis, Sediments and Paleo-Environments. Kluwer academic publishers, Dordrecht, The Netherlands.

Pluymakers, A., Maya, K., Francois, R., 2017. How microfracture roughness can be used to distinguish between exhumed cracks and in-situ flow paths in shales. J. Struct. Geol. 94, 87-97.

Sampath, K.H.S.M., Perera, M.S.A., Ranjith, P.G., Matthai, S.K., Li, D.Y., 2019. Qualitative and quantitative evaluation of the alteration of microfracture characteristics of supercritical CO2-interacted coal. J. Supercrit. Fluids 147, 90-101.

Wang, L., Dai, C., Xue, L., 2018. A semi-analytical model for pumping tests in finite heterogeneous confined aquifers with arbitrarily shaped boundary. Water Resour. Res. 54 (4), 3207-3216. 
Williamsstroud, S., Ozgen, C., Billingsley, R., 2013. Microseismicity-constrained discrete fracture network models for stimulated reservoir simulation. Geophysics 78 (1), B37-B47.

Zeng, L., Gao, C., Qi, J., Wang, Y., Li, L., Qu, X., 2008. The distribution rule and seepage effect of the fractures in the ultra-low permeability sandstone reservoir in east Gansu Province, Ordos Basin. Sci. ChinaSer. D Earth Sci. 51 (2), 44-52.
Zhu, H.Y., Zhao, Y.P., Feng, Y.C., Wang, H.W., Zhang, L.Y., McLennan, J.D., 2019. Modeling of fracture width and conductivity in channel fracturing with nonlinear proppant-pillar deformation. SPE J. https://doi.org/10.2118/194500-PA. 